\title{
DINÂMICA TERRITORIAL E SOCIAL DOS PESCADORES ARTESANAIS DE NOVO AIRÃO-AM
}

\author{
Maria Ferreira de Oliveira Filha ${ }^{32}$ \\ Elenise Faria Scherer ${ }^{33}$ \\ Antônia Mara Raposo Diógenes ${ }^{34}$
}

\begin{abstract}
RESUMO
O presente artigo tem por objetivo analisar as dificuldades enfrentadas por pescadores artesanais para realizar a pesca no município de Novo Airão, já que $80 \%$ da área do município é de Unidades de Conservação. Tratase de uma pesquisa qualitativa que se utilizou de fonte bibliográfica, documental, entrevistas semiestruturadas e observação direta. Com a realização da pesquisa observou-se que o trabalho na pesca em Novo Airão é cercado por conflitos socioambientais envolvendo o acesso aos recursos naturais, decorrentes da implantação de Unidades de Conservação de uso restrito no município. Com o objetivo de propor soluções para o conflito estão sendo realizadas várias negociações entre o ICMBio e as entidades representativas dos pescadores para construção de acordos de pesca no âmbito do Parque Nacional de Anavilhanas.
\end{abstract}

Palavras Chave: Unidades de Conservação, Pescadores Artesanais, Conflitos socioambientais.

\section{TERRITORIAL AND SOCIAL DYNAMICS OF ARTISANAL FISHERWOMAN IN NOVO AIRÃO-AM}

\begin{abstract}
This article aims to analyze the difficulties faced by artisanal fisherwoman to carry out fishing in the municipality of Novo Airão, since $80 \%$ of the municipality's area is of Conservation Units. It is a qualitative research that used a bibliographic, documentary source, semi-structured interviews and direct observation. With the realization of the research it was observed that the work in fishing in Novo Airão is surrounded by socio-environmental conflicts involving access to natural resources, resulting from the implementation of Conservation Units for restricted use in the municipality. In order to propose solutions to the conflict, several negotiations are being carried out between ICMBio and the representative entities of fisherwoman for the construction of fishing agreements within the scope of the Anavilhanas National Park.
\end{abstract}

Keywords: Conservation Units, Artisanal Fisherwoman, Socio-environmental conflicts.

\section{INTRODUÇÃO}

A criação e a manutenção de Unidades de Conservação (UC) são estratégias adotadas pelo Estado para a conservação dos recursos naturais. Nessa perspectiva, a lei $n^{\circ}$ 9.985/2000 define UC como espaço territorial e seus recursos ambientais, incluindo as águas jurisdicionais, com características naturais relevantes, legalmente instituído pelo Poder Público, com objetivo de conservação e limites definidos, sob regime especial de administração, ao qual se aplicam garantias adequadas de proteção $\left(\right.$ Art. $\left.2^{\circ}\right)$.

\footnotetext{
32 Doutoranda do Programa de Pós-Graduação em Sociedade e Cultura na Amazônia (PPGSCA/UFAM). E-mail: mariaferreira_oliveira@hotmail.com

${ }^{33}$ Professora do Programa de Pós-Graduação em Sociedade e Cultura na Amazônia (PPGSCA/UFAM) e pesquisadora do Conselho Nacional de Desenvolvimento Científico e Tecnológico (CNPQ). E-mail: elenisefaria@gmail.com

${ }^{34}$ Doutoranda do Programa de Pós-Graduação em Ciência do Ambiente e Sustentabilidade na Amazônia UFAM.

E-mail: antoniaraposo@gmail.com
} 
Com essa configuração, as UC existentes no Brasil estão divididas em dois grupos específicos: os de proteção integral e os de uso sustentável. As UC de proteção integral têm como objetivo preservar a natureza e possibilitar a realização de pesquisas científicas; a presença humana é restrita à visitação, incluem-se a estação ecológica; a reserva biológica; parque nacional, estadual e natural municipal; o refúgio de vida silvestre e o monumento natural (BRASIL, 2000).

Por outro lado, as UC de uso sustentável garantem às populações tradicionais a permanência no interior das unidades de conservação e permitem o uso dos recursos naturais mediante a elaboração e a implementação de um plano de manejo, assegurando a participação da população local. Neste grupo, incluem-se a área de proteção ambiental; a área de relevante interesse ecológico; a floresta nacional, estadual e municipal; a reserva extrativista; a reserva de fauna; a reserva de desenvolvimento sustentável e a reserva de patrimônio particular natural (BRASIL, 2000). O reconhecimento do direito à permanência de populações tradicionais em seus territórios redefinidos como UC é um fato recente na história da legislação ambiental no Brasil. Para Moura et al. (2016), até o final da década de 1990 as UC de proteção integral eram o modelo predominante, representado pelos parques e reservas ambientais que determinava a retirada das populações residentes nessas áreas porque havia entendimento de que sua presença era uma ameaça à integridade dos ambientes a serem preservados.

Foi sob essa perspectiva que a política ambiental idealizada pelo governo do Amazonas iniciou o Projeto Corredores Ecológicos em 1998, criando uma série de áreas protegidas na região central da Amazônia, as quais em quase sua totalidade, foram destinadas à proteção integral.

Em Novo Airão, as UC federais e estaduais foram criadas em tempos diferentes, permeadas de processos políticos, cada qual com sua história, e de conflitos entre moradores e instituições. Sob essa ótica, Novo Airão tem cerca de $80 \%$ de seu território ocupado por UC. A área ocupada contém sete UC das esferas federais, estaduais ${ }^{35}$. Dessa forma, o município apresenta-se como um verdadeiro mosaico de áreas protegidas.

Ressalta-se que Novo Airão dá acesso, entre outras, a duas grandes áreas de proteção ambiental: os Parques Nacionais de Anavilhanas e do Jaú. Assim, a sede do Município está localizada na zona de amortecimento do PARNA Anavilhanas ${ }^{36}$.

\footnotetext{
35 Parque Nacional de Anavilhanas, o Parque Nacional do Jaú, o Parque Estadual Rio Negro Setor Norte, a Área de Proteção Ambiental (APA) Margem Direita do Rio Negro, a APA Margem Esquerda do Rio Negro, a Reserva de Desenvolvimento Sustentável (RDS) do Rio Negro e as Terras Indígenas Waimiri Atroari.

${ }^{36}$ É o entorno de uma unidade de conservação, onde as atividades humanas estão sujeitas a normas e restrições específicas, com o propósito de minimizar os impactos negativos sobre a unidade (Lei n ${ }^{\circ}$ 9.985/2000, art 29, Inc XVIII).
} 
O Parque Nacional de Anavilhanas foi criado pelo Decreto n 86.061, de 02 de junho de 1981, como Estação Ecológica (ESEC), tendo sido recategorizado à Parque em 2008 por meio da lei $\mathrm{n}^{\circ}$ 11.799 , de 29 de outubro. Possui uma área de aproximadamente $340.831,53 \mathrm{~km}^{2}$, abrangendo os municípios de Manaus (28\%) e Novo Airão (72\%). Configura-se como um dos maiores arquipélagos fluviais do mundo, contendo cerca de 400 ilhas.

O Parque Nacional do Jaú foi criado pelo Decreto n ${ }^{\circ} 85.200$, de 24 de setembro de 1980, possui uma área de $2.272 \mathrm{~km}^{2}$, sendo atualmente o maior Parque Nacional do Brasil e o segundo maior do mundo em florestas tropicais contínuas (IBAMA/FVA, 1998). O PARNA Jaú abrange os municípios de Novo Airão e Barcelos. O Parque é assim denominado por ser banhado pelo rio Jaú (do tupi ya 'u), e também de um dos maiores peixes brasileiro, o jaú (Paulicea luetkern).

Atualmente, a gestão dos Parques Nacionais de Anavilhanas e do Jaú é de responsabilidade do Instituto Chico Mendes de Conservação da Biodiversidade (ICMBio). Entretanto, o processo de implantação dos Parques de Anavilhanas e Jaú, gerou enormes conflitos e impactos decorrentes da desterritorialização de grupamentos sociais que habitavam a região.

Em linhas gerais, podemos dizer que a criação e a gestão das UC na atualidade vêm se constituindo por meio da intervenção Estatal e da iniciativa privada, visando a conservação da biodiversidade e o desenvolvimento sustentável. "Entretanto, esse processo tem sido acompanhado por conflitos e impactos decorrentes da desterritorialização de grupamentos sociais (tradicionais ou não) em várias partes do mundo" (VALEJO, 2009, p. 01). E, no Amazonas, não é diferente.

Little (2001) explica que os conflitos socioambientais envolvem três dimensões: os conflitos em torno do controle sobre os recursos naturais; os conflitos em torno dos impactos ambientais e sociais gerados pela ação humana e natural; e, os conflitos em torno do uso dos conhecimentos ambientais. Em muitos casos, os conflitos socioambientais são gerados, principalmente, devido à implantação de UC de proteção integral em territórios tradicionalmente ocupados, como observado no município de Novo Airão.

Segundo Rodrigues (2010), a pesca em Novo Airão possui uma dinâmica espacial peculiar, o que torna a pesca comercial questionável, obrigando os pescadores a lutar por mais áreas de pesca. Enquanto nada se resolve, muitos pescadores entram de forma clandestina nas áreas dos Parques Nacionais de Anavilhanas e do Jaú para retirar o sustento de suas famílias.

Neste sentido, o presente artigo tem por objetivo descrever sobre as dificuldades enfrentadas por pescadores artesanais para realizar a pesca no município de Novo Airão, já que grande parte da área do município é de Unidades de Conservação. O município fica situado na microrregião do Rio 
Negro, com distância de aproximadamente $195 \mathrm{~km}^{37}$ da capital do estado, Manaus. Com população de cerca de 14.723 habitantes, sendo assim distribuídos: 9.499 na zona urbana e 5.224 na zona rural (IBGE, 2010).

A pesquisa foi realizada durante o ano de $2017^{38}$, com pescadores artesanais e com representantes das Colônias de Pescadores Z-34 e AM-34. Metodologicamente, foi conduzida por meio de uma abordagem qualitativa, com o uso de entrevistas semiestruturadas, observação direta e análise documental (referente à atividade pesqueira e as políticas de proteção ambiental) que permitiu de forma sistemática a identificação de aspectos significativos sobre a realidade dos pescadores artesanais em Novo Airão.

O pescador artesanal é aquele que explora vários ambientes aquáticos, sozinho, em parcerias ou com a ajuda do grupo familiar; captura espécies variadas de pescado utilizando instrumentos de pesca diversificados com base nos conhecimentos tradicionais adquiridos sobre a natureza (DIEGUES,1983).

\section{Os pescadores artesanais e os limites impostos}

“O pescador de Novo Airão virou ladrão! devido às áreas de pesca ficarem dentro das Unidades de Conservação, assim, somos obrigados a entrar escondidos à noite no Parque, para poder pescar e alimentar nossas famílias” (Sr. P..,pescador artesanal, entrevista realizada em outubro de 2017).

Em Novo Airão os pescadores artesanais encontram muitas dificuldades para exercer a atividade pesqueira, em primeiro lugar, por causa dos limites das áreas de conservação, onde parte dos ambientes aquáticos não são acessíveis para a pesca. Assim, os pescadores são proibidos de pescar nesses locais, e acabam entrando escondidos dentro das UCs, principalmente à noite, para pescar. De acordo com este pescador artesanal:

O pescador não pode entrar na reserva para pescar, não pode pegar um bicho de casco para comer com a família, aqui o caboclo é acostumado a pegar uma caça, um tracajá para comer, é uma tradição! Agora a gente é proibido de pegar esse tipo. Então o jeito é pegar escondido. Como se fosse um ladrão! o pescador entra dentro do Parque para roubar o alimento para sua família... Essa é a vida do pescador em Novo Airão! (Sr.I.B.., pescador artesanal, entrevista realizada em outubro de 2017).

\footnotetext{
${ }^{37} \mathrm{O}$ trajeto de Manaus (capital do estado do Amazonas) ao município de Novo Airão pode ser realizado de carro ou de ônibus, através da Ponte Rio Negro, pela rodovia AM-070 (Estrada Manoel Urbano) e, no Km 80, vire à direita e siga pela rodovia AM-352 que leva até Novo Airão. O percurso dura em média 2horas e 51minutos. A viagem também pode ser feita por via fluvial em barco regional (9 horas de viagem).

38 Este artigo é síntese de algumas discussões realizada no âmbito de minha dissertação de mestrado, intitulada "Pescadores Artesanais de Novo Airão: Dos conflitos socioambientais aos direitos da Seguridade Social", apresentada ao Programa de Pós-Graduação em Serviço Social e Sustentabilidade na Amazônia (PPGSS-UFAM) em 2017, que recebeu financiamento do Conselho Nacional de Desenvolvimento Científíco e Tecnológico (CNPQ).
} 
O município de Novo Airão como já mencionado, tem $80 \%$ de seu território coberto por Unidades de Conservação que abrangem o Parque Nacional de Anavilhanas, o Parque Nacional do Jaú e as demais Reservas Estaduais, o que dificulta a reprodução do modo de vida dos pescadores artesanais e demais trabalhadores moradores da zona rural do município. De acordo com o Presidente da Colônia AM-34:

\begin{abstract}
Quando eu morava na zona rural aqui em João Peri, faz muitos anos, ainda não existia esses Parques, eles foram criados nos anos 80 . A gente pescava não tinha problema nenhum, mas hoje tá difícil, porque Novo Airão tá dentro dos Parques. Dizem que é $15 \%$ que nós temos liberado, mas fica lá num rio que não tem peixe, realmente não adianta mentir. Nós pescamos no Parque, tem muito peixe graças a Deus, não é aquele barco grande, são canoas pequenas, rabetas, caixas de isopor pra levar o peixe (Presidente da Colônia de pescadores AM-34, entrevista realizada em outubro de 2017).
\end{abstract}

Nesse cenário contraditório, muitos pescadores ignoram as restrições impostas ao acesso dos recursos pesqueiros e entram clandestinamente no interior dos Parques, exercendo a pesca em locais proibidos. Segundo Illenseer (2011), os pescadores de Novo Airão são chamados de "pescadores sem água”, devido às restrições impostas ao acesso dos ambientes de pesca que ficam dentro dos Parques de Anavilhanas e Jaú.

Os pescadores artesanais reclamam da fiscalização dos órgãos governamentais, pois segundo eles é abusiva, porque, quando são abordados por esses agentes, além do peixe também são apreendido o material de pesca (canoa, malhadeira, anzol, dentre outros).

Para Rodrigues (2014), os conflitos entre os pescadores artesanais e os agentes do ICMBio existem por conta da inexistência de sinalização na parte do Rio Negro dentro das UCs. Em alguns casos, ocorrem injustiças com os pescadores artesanais ao terem seus apetrechos de pesca apreendidos com a alegação de que a produção ocorre dentro das áreas do PARNA Anavilhanas, sem a devida comprovação. "O território é para os pescadores meio de produção e para o Estado é uma área de conservação" (Idem, p. 8, 2010).

De uma maneira geral, os pescadores entrevistados, indicam as seguintes regiões como os principais locais utilizados para a pesca em Novo Airão: os rios Paudari e Jauperi (área de livre acesso), Rio Branco (fora das áreas de reservas), Unini (área de acordo de pesca); Os lagos: Apacu Grande, Boto, Canaurí, Lago do Ambé, Lago do Capim, Lago do Cupim, Lago do Boiuasul, situados dentro das Unidades de Conservação.

Os Parques do Jaú e Anavilhanas representam parte dos ambientes aquáticos não acessíveis para a pesca comercial. É possível dizer que o "que sobrou" para os pescadores é a região compreendida entre os dois Parques e o entorno (entre o Rio Jauaperi até o Rio Branco), que já estaria no limite entre o Baixo e o Médio Rio Negro (ILLENSEER, 2011). Ainda para o autor, estes locais, 
que seriam considerados de "acesso livre" para a pesca artesanal comercial, foram em parte “interditados" por dois acordos de pesca solicitados pelas comunidades ribeirinhas e reconhecidos pelo IBAMA. É o caso do Rio Unini (2004) e do Rio Jauaperi (2006). Os acordos de pesca foram reivindicados devido à sobre-exploração dos recursos pesqueiros nos dois rios, além da promulgação do Decreto Rio Negro (2011). De outro modo, os acordos de pesca do rio Unini e Jauaperi são restritivos para a pesca comercial e o decreto Rio Negro proíbe a pesca comercial do tucunaré (Cichla spp.) e aruanã (Osteoglossum bicirrhosum). Na Tabela 1, descrevem-se as regras entre instrumentos de gestão:

Tabela 1- Tabela comparativa entre as regras referentes à pesca comercial

Rios/Ambientes

Decreto Rio Negro

Rio Unini (setor II do acordo d

pesca )

Rios Jauaperi, Unini (setor I)
Sistemas de regras (cota, sazonalidade e apetrechos)

Cota: barco de 5 toneladas (1 viagem por mês);

Restrição: proibida a pesca do tucunaré e aruanã preta

Cota: barco de até 3 toneladas (rodízio de 3 barcos por mês/sort período de setembro a dezembro.

Pesca de subsistência alimentar das comunidades (trocas intern

Fonte: Illenseer (2011).

Na região do Baixo Rio Negro, os dois acordos de pesca e o decreto "Rio Negro" impõem barreiras para os pescadores artesanais de escala comercial exercer em sua atividade na região. De acordo com a narrativa do presidente da Colônia Z-34, os locais "livres" para a pesca são insuficientes e em alguns casos, extremamente distantes da sede do município de Novo Airão.

Destaca-se, ainda, na narrativa dos entrevistados, que as principais espécies de peixes capturadas são: Tambaqui (Colossoma macropomum), Acará-Cascudo (Caquetaia spectabilis), Acará-Bararuá (Uaru amphiacanthoides), Acará-Açu (Astronotus ocellatus), Acará-Jarupari (Satanoperca jurupari), Tucunaré (Cichla spp.), Matrinxã (Brycon amazonicus), Jaraqui (Prochilodus brama), Pacu (Mylossoma spp) Aruanã (Osteoglossum bicirrhosum), Traíra (Hoplias malabaricus), Aracu (Leporinus friderici), Pirara (Phractocephalus hemioliopterus), Surubim (Pseudoplatystoma fasciatum) e Filhote (Brachyplatystoma filamentosum). Estas espécies são capturadas pelos seguintes apetrechos de pesca: malhadeiras, tarrafa, linha de mão, arpão e espinhel, anzol e zagaia. $\mathrm{O}$ uso dos instrumentos se difere de acordo com a diversidade das espécies capturadas e o tipo de sazonalidade dos recursos explorados. 


\section{A organização da cadeia produtiva da pesca}

Outra dificuldade enfrentada pelos pescadores artesanais diz respeito à falta de infraestrutura para comercializar o pescado, em linhas gerais, não existe local "adequado" para escoar e armazenar o pescado, o que acaba favorecendo a atividade dos atravessadores na região.

Em Novo Airão, até 1992 existia um mercado para vender o pescado, hoje o local encontra-se abandonado. Segundo a narrativa do presidente da Colônia de Pescadores AM-34, virou um sucatão, uma lixeira (Figura 1), bem como a balsa frigorífica que foi doada pela SUFRAMA ao município no final do ano 2000, também encontra-se desativada, conforme a Figura 2:

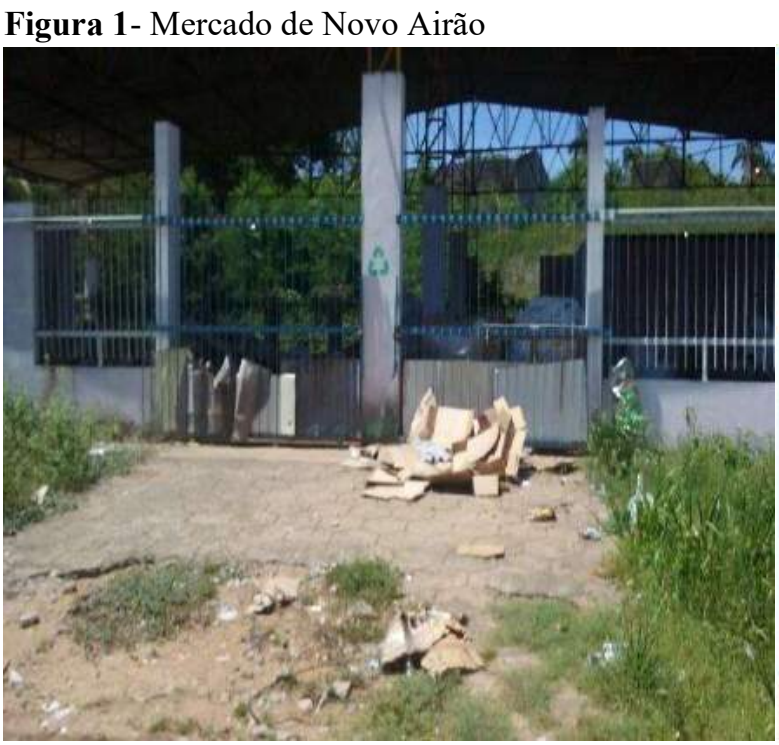

Fonte: Acervo da pesquisadora 2017
Figura 2- Balsa Frigorífica

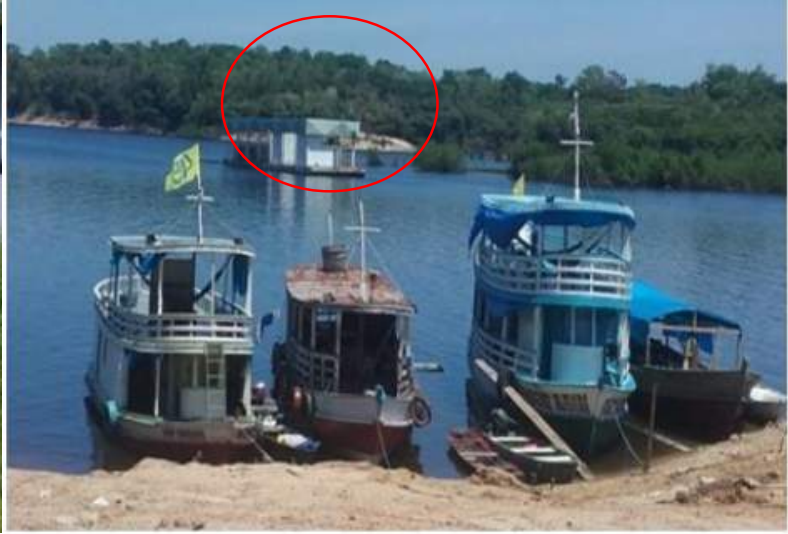

Fonte: Acervo da pesquisadora 2017

A narrativa do presidente da Colônia de Pescadores Z-34 destaca que, quando o município recebeu essa balsa no fim do ano de 2000, ela veio com o nome de "terminal pesqueiro de Novo Airão", mas a prefeitura mudou o nome para Porto de Novo Airão. O município não possui mercados, feiras e nem frigoríficos para armazenamento e beneficiamento do pescado. Os pescadores são obrigados a realizar a venda direta em carinho de mão ou bicicleta cargueira nas ruas da cidade, para pequenos comerciantes, donos de restaurantes ou nas residências. O peixe é vendido em cambadas ${ }^{39}$, e o valor varia de acordo com a espécie capturada. A outra opção é vender o pescado para atravessadores por um preço muito baixo:

Aqui em Novo Airão não tem onde armazenar o peixe, por isso quando eu vou pescar, que eu vejo que eu estou com uma faixa de 200 a $300 \mathrm{~kg}$ eu já tô me recolhendo do lago pra não 39 Cambada trata-se de uma quantidade de peixe colocada em um cipó, fibras ou galho de árvores para serem vendidos
de uma só vez. As cambadas levam de 5 a 10 peixes; estes podem ser de espécies variadas. 
acontecer o caso de estragar o peixe e a gente ter prejuízo, aí eu venho, eu mesmo saio na rua pra vender o peixe boto numa caixa de isopor dentro de um carinho de mão e vou embora, a maioria eu vendo pro atravessador que aqui tem (Sr. R.J.., entrevista realizada em outubro de 2017).

O principal ponto de venda, de chegada e de saída do pescado in natura é o Porto do Padre. No local, existia um pequeno flutuante onde ficavam guardados os barcos da Fundação Nacional da Saúde (FUNASA), que atualmente ocupou a forma de terminal pesqueiro. A Figura 3 é ilustrativa:

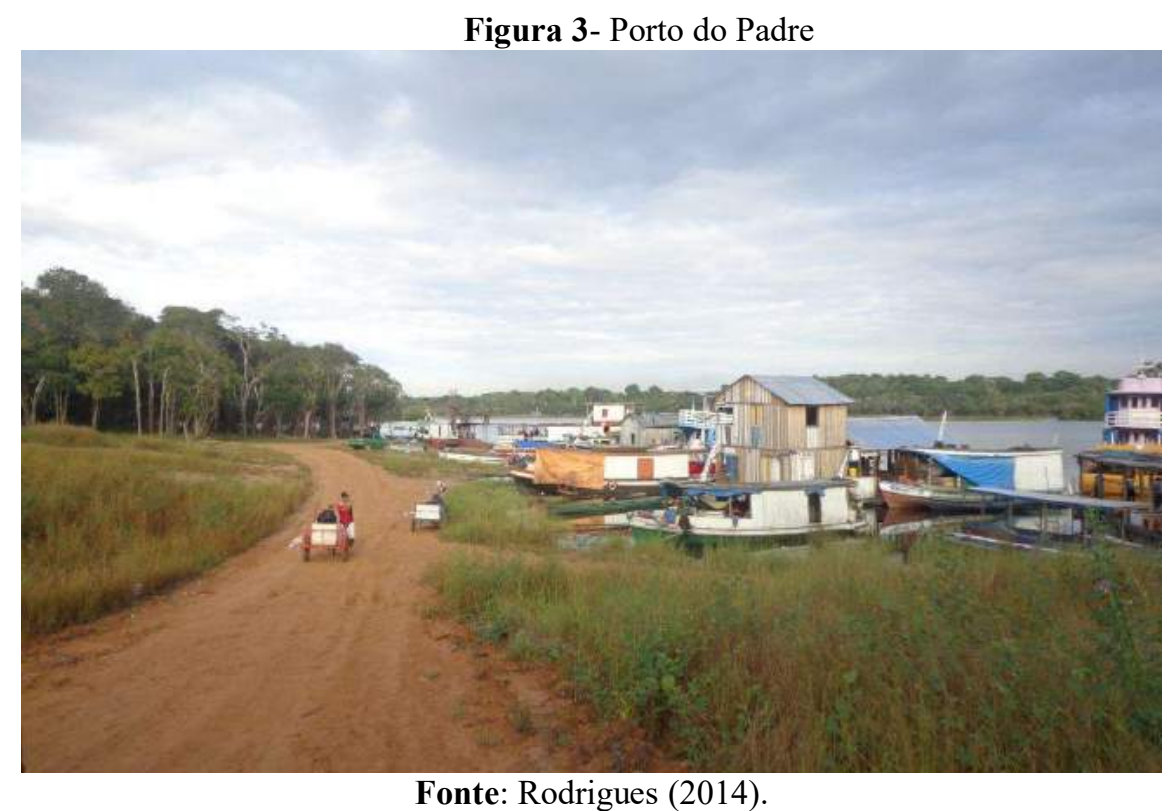

Em Novo Airão, os pescadores artesanais são representados por quatro entidades: Colônia Z34; Associação dos Pescadores de Novo Airão (APNA); Colônia dos Pescadores de Novo Airão AM -34 e Sindicato dos Pescadores no Amazonas (SINDPESCA). A Colônia Z-34 surgiu em Novo Airão em 02 de maio de 1999, mas somente em 16 de fevereiro de 2002 começou a funcionar legalmente. Atualmente a entidade tem 404 pescadores associados, sendo 153 mulheres e 251 homens. $75 \%$ dos associados são oriundos de comunidades próximas a Novo Airão.

A Colônia AM-34 foi criada em 2010, depois da divisão interna da Colônia Z- 34. Tal separação deveu-se à discordância administrativa e aos interesses político-partidários entre seus membros. Assim, foi realizada uma assembleia com a federação dos pescadores e juridicamente foi mudada a sigla para AM. Todavia, a AM-34 usa o mesmo CNPJ da Colônia Z-34 para funcionar. A Colônia atualmente possui 840 associados, mas nem todos possuem o Registro Geral da Pesca.

Em julho de 2002 foi criado a APNA dentro da Colônia Z-34, por causa de divergências políticas entre seus membros. Isso ocorreu quando houve a primeira eleição da diretoria após o reconhecimento legal da Z-34; a chapa que foi derrotada resolveu se desvincular da Colônia e fundar a associação dos Pescadores de Novo Airão. 
Outra entidade é o SINDPESCA, criado em 2008 devido a conflitos internos da diretoria da APNA, sobre a gestão de um projeto executado com apoio do Projeto Corredores Ecológicos (PCE). Houve uma divisão interna da associação (ILLENSEER, 2011), culminando na saída do presidente na ocasião e quem criou o Sindicato dos Pescadores do Estado do Amazonas, em 2010.

Destaca-se na narrativa do presidente da Colônia de Pescadores AM-34, que o conflito interno entre ambas as entidades está relacionada a uma visão de que a colônia Z-34, ligada à Federação das Colônias dos Pescadores, deveria ser a única representante dos pescadores em Novo Airão. “Aqui a Federação, usa aquele sistema de Coronel de Barranco de antigamente, ela bota quem ela quer lá no sistema”. A partir da pesquisa de campo, verificamos que essa relação conflituosa se manifesta nas disputas judiciais, nas quais a Colônia de Pescadores Z-34 tem solicitado, nos tribunais de justiça, o direito de ser a única entidade que pode solicitar o seguro defeso dos pescadores artesanais.

A narrativa do presidente da Colônia de Pescadores Z-34 deixa transparecer que a Federação lhe proíbe de passar qualquer informação referente aos direitos sociais dos pescadores à Colônia de Pescadores AM-34. O presidente afirmou que "Essa relação é muito conflituosa, agora que as coisas não estão mais dando certo, ele tá me procurando em busca de informações, mas a Federação me proíbe de passar informação" (Presidente da Colônia de pescadores Z-34, entrevista realizada em outubro de 2017).

Entretanto, a Colônia de Pescadores AM-34 depende dos registros e assinaturas dos representantes legais da Colônia de Pescadores Z-34 para poder funcionar, assim como a APNA, como é retratado na narrativa a seguir.

\begin{abstract}
Então, é assim que é o sistema daqui. Quando é na hora dos benefícios quem tem que assinar sou eu, as declarações. Quando ocorre as indeferições dos benefícios assinados pelas outras entidades, elas recorrem a Colônia Z-34, mas eu não assino, a federação não permite. Eu posso assinar vindo para a Colônia, ver o que eu posso fazer, salvo que não me prejudique, porque eu não aceito propina de ninguém, seja quem for, eu não aceito. (Presidente da Colônia de pescadores Z-34, entrevista realizada em outubro de 2017).
\end{abstract}

Como podemos observar, a Colônia Z-34 tem maior importância, pois é a única reconhecida por lei como entidade representativa dos pecadores em Novo Airão, de acordo com Art. $\mathrm{n}^{\mathrm{o}} .8^{\mathrm{o}}$ da CF de 1988, que dispõe sobre a organização das entidades representativas dos pescadores. No entanto, é a Colônia AM -34 que possui o maior número de associados: cerca de 840 pescadores.

Durante um diagnóstico realizado no mês de Outubro de 2015, juntamente com a equipe do IDAM sobre os principais problemas enfrentados pelos pescadores de Novo Airão, a reunião aconteceu na Câmara dos Vereadores do Munícipio. Na ocasião, compareceram 26 pescadores e pescadoras (sendo vinte homens e seis mulheres); eles elencaram como um dos graves problemas 
enfrentados pela categoria a disputa entre as quatro entidades, e manifestaram o desejo de terem uma única entidade representativa (Figura 4).

Figura 4- Reunião com pescadores

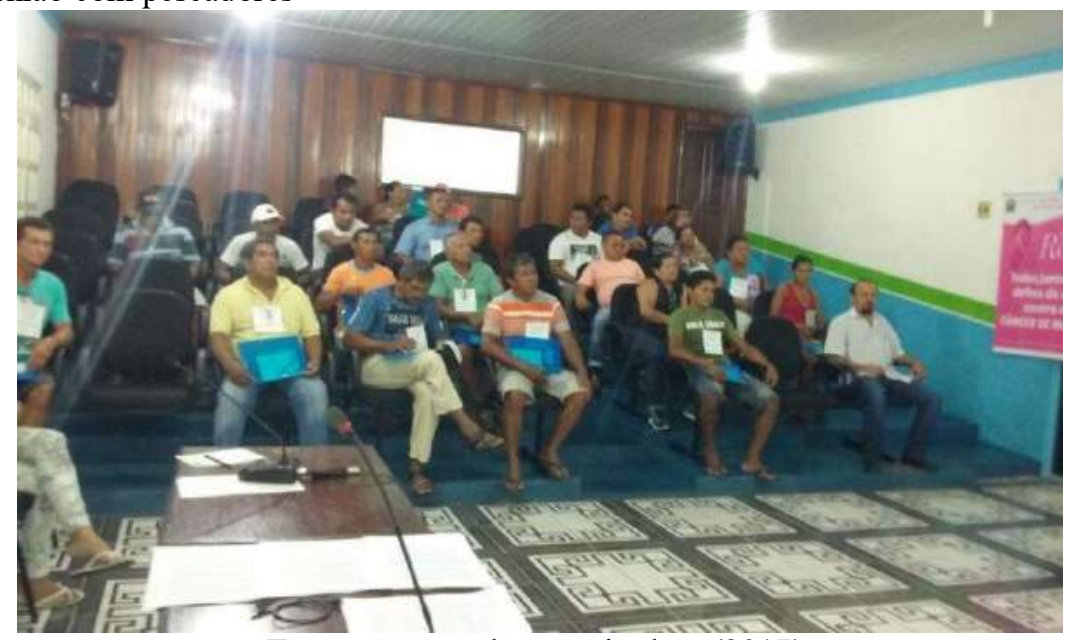

Fonte: Acervo da pesquisadora (2017).

Ressalta-se, ainda, que o envolvimento dos líderes das entidades representativas dos pescadores com as pautas partidárias políticas do município fizeram com que não houvesse consenso, mas divergências políticas entre elas (RODRIGUES, 2014). Evidenciando o quanto a busca pelo poder é mais importante que a luta dos pescadores pelo direito de exploração dos recursos pesqueiros. $\mathrm{Na}$ narrativa de alguns pescadores, esse conflito chega até a atrapalhar o acesso aos direitos sociais, principalmente aos previdenciários.

Com base no exposto, é possível imaginar que os pescadores artesanais queiram abandonar esta profissão no futuro. Durante o trabalho de campo, entrevistamos 11 pescadores. Destes, apenas dois manifestaram o desejo de que os filhos venham viver da pesca em Novo Airão, como é retratado nas narrativas a seguir:

Eu prefiro que os meus filhos vivam da pesca, com certeza, porque é o único meio que eu sei lidar com redes, com zagaia, com as coisas que é usado na pesca (Sr. S.B.., pescador artesanal, entrevista realizada em outubro de 2017).

Sou mãe de quatro filhos, às vezes eles me acompanham dia de sábado ou domingo, por que eles estudam, então às vezes eles me acompanham para ter uma experiência de como pescar. Se for a sorte deles virarem pescador eu vou ter que aceitar, agora se tiver uma outra coisa melhor pra eles pela frente eu prefiro. Eu pesco com o meu marido, quando ele não vai eu pesco sozinha (Sra. R.S.., entrevista realizada em outubro de 2017).

Tenho duas filhas pequenas, na popa da canoa elas vão comigo quando eu vou pró gapó. Mas eu não quero que elas sejam pescadoras, pra mim é mais o estudo, é muito difícil trabalhar na pesca, cada dia ficando pior, porque num 
tem área tão fechando tudo, tem bem pouca área para trabalhar (Sra. T.A.F.., entrevista realizada em outubro de 2017).

Diante da política ambiental territorialmente restritiva ao acesso e ao uso dos recursos pesqueiros, somados aos aparentes conflitos entre as quatro entidades representativas dos pescadores artesanais, cabe perguntar: no futuro, o número de pescadores artesanais tende a diminuir ou se extinguir no município?

Em linhas gerais, de acordo com dados do extinto Ministério da Pesca e Aquicultura (MPA, 2015), em 2010 estavam devidamente cadastrados em seu sistema 1.244 pescadores artesanais em Novo Airão. Em 2011, este número saltou para 1.336 pescadores. Em 2015 o número de pescadores cadastrado era de 1.300. Já em 2020, o número de pescadores cadastrados diminuiu gradativamente, dados do Portal da Transparência ${ }^{40}$ mostram que existem aproximadamente 695 (seiscentos e noventa e cinco) pescadores artesanais ativos, inscritos no Registro Geral da Pesca (RGP).

Sobre essa ótica, podemos supor que o número de pescadores artesanais pode ter diminuído devido as novas exigências institucionais decorrente da portaria SEAP/MAPA n ${ }^{0} 11$ de 2016. Essa portaria utilizou a previsão legal de suspender a licença daqueles pescadores que não faziam o relatório da atividade pesqueira e que não realizavam a manutenção anual de seu cadastro no sistema do INSS.

Outra medida que pode ter contribuído para a diminuição do número de pescadores registrados pode estar relacionado as mudanças introduzidas pelo Decreto $n^{\circ} 8.424 / 2015$, que mudou as regras de acesso ao seguro-defeso, ao classificar/reclassificar o conceito de pescador artesanal posto na lei $\mathrm{n}^{\mathrm{o}} 10.779 / 2003\left(\mathrm{Art}^{\circ} \mathrm{1}^{\circ}\right.$ ), ela vai criar a categoria de pescador profissional exclusivo, aquele que exerce a pesca ininterruptamente, individualmente ou em regime de economia familiar. Estabeleceu-se que a concessão do seguro defeso não será extensível às atividades de apoio à pesca (os trabalhos de confecção e de reparos em embarcações de pequeno porte, de artes e apetrechos de pesca, de processamento do produto da pesca artesanal), prejudicando, sobretudo, as mulheres pescadoras que estão em maior número no exercício dessas atividades.

Sobre o modo de vida dos pescadores em Novo Airão, muitos destes pescadores que moram na sede do município também mantém sítios na zona rural. Nesse sentido, observamos que grande parte dos pescadores permanecia na cidade, apenas alguns dias da semana (de segunda a quinta-feira), os demais dias (de sexta-feira a domingo), deslocam-se para a zona rural. De acordo com os estudos realizados por Silva (2009), o pescador artesanal de Novo Airão mantém residências em ambas as

40 Disponível em:http://www.portaltransparencia.gov.br/localidades/1303205-novo-airao?ano=2020. Acesso em 28/03/2021. 
regiões (rural/urbano) o que forma um contínuo entre "campo e cidade". Como salienta um dos pescadores entrevistados:

\footnotetext{
Eu tô na pesca direto mesmo há 25 anos, mas eu também sou agricultor, faço as duas partes, quando eu tô trabalhando na roça eu paro a pescaria pra fazer o trabalho na roça, quando eu acabo de lá eu vou pra pescaria. A roça é mais é pra comer que eu planto e a pescaria é para vender mesmo (Sr. R.S.., entrevista realizada em outubro de 2016).
}

Nas palavras de Furtado (2006), o pescador artesanal amazônico desenvolve em seu cotidiano práticas econômicas e culturais singular, "cuja a vida social e material transita entre a terra e a água, a terra e a floresta, entre a terra e o mar" (p. 162). Os pescadores ouvidos nesta pesquisa afirmaram ser pescadores artesanais desde que eram crianças, e que o ofício da pesca lhes foi ensinado pelos pais ou algum amigo da família.

Sobre os territórios de pesca, Pereira (2004) argumenta que os pescadores na Amazônia têm reivindicado o controle de uso e acesso das áreas de pesca. Para Almeida (2006), os locais de pesca são específicos, e desta forma, os pescadores não almejam o território em si, mas as garantias do usufruto.

Assim, em Novo Airão, os pescadores lutam para conquistar o privilégio de acessar os locais de pesca que ficam no interior da UCs de proteção integral. Como consequência dessa resistência estão sendo realizadas várias negociações com o ICMBio para construção de acordos de pesca no PARNA Anavilhanas.

Por se tratar de uma UC de proteção Integral, o uso dos recursos pesqueiros é proibido legalmente. Na visão do ICMBio (2016), a pesca de subsistência é tolerada, pois dela depende a sobrevivência das comunidades tradicionais. Contudo, sem regulamentação, o que gera são inúmeros conflitos entre moradores do entorno do PARNA Anavilhanas e a gestão da UC, o que se traduz num cenário de insegurança tanto para a equipe gestora do parque, quanto para os pescadores artesanais.

Com o objetivo de propor soluções para o conflito foi, criado um Grupo de Trabalho (GT Pesca) em 2008 (embora tenha sido paralisado várias vezes), no âmbito do Conselho Consultivo do Parque Nacional de Anavilhanas, sendo reativado em 2015 e acorda-se um planejamento de ações, que propõe a elaboração de um documento técnico, com a proposta de regulamentação e, por outro, a definição de estratégias jurídicas e políticas para sua implementação. 
Para a construção do documento técnico, foi necessária a realização de um diagnóstico socioeconômico sobre a atividade pesqueira no parque, para qualificar as informações e subsidiar a regulamentação proposta ${ }^{41}$.

Nesse contexto, foi realizado um planejamento junto ao Grupo de Trabalho da Pesca de Novo Airão. O fórum de acompanhamento dessa consultoria, composto por instituições que atua na região, como o Instituto Chico Mendes (ICMBio), Colônia de Pescadores Z-34 e AM-34 de Novo Airão, Associação de Pescadores de Iranduba e de Novo Airão, SEMA/DEMUC e INP, para caracterizar a pesca de subsistência das comunidades ribeirinhas localizadas no entorno do PARNA Anavilhanas.

Esse planejamento agrupou as comunidades do entorno em 14 polos, distribuídos de acordo com a proximidade entre elas, considerando a cidade de Novo Airão como um único polo. Foi encaminhado um convite formal constando um breve resumo das atividades previstas, as datas e os horários das reuniões e a solicitação da participação de cinco pescadores experientes de cada comunidade para se reunir no local definido para cada polo (Idem, 2016).

As reuniões foram divididas em três etapas: a primeira teve como objetivo o preenchimento de um formulário com informações sobre peixes utilizados para a subsistência, além dos locais de pesca comumente visitados pelos pescadores. De posse dessas informações, foi utilizada a técnica de mapeamento participativo para identificar as áreas numa imagem satélite da região estudada, como é possível conferir na Figura 5:

\footnotetext{
${ }^{41}$ É nesse contexto que a WCS-Brasil, através do projeto "Consolidação da Conservação no Baixo Rio Negro", com recursos da Fundação Moore, vem apoiar o Grupo de Trabalho Pesca do Parque Nacional de Anavilhanas na elaboração do diagnóstico socioeconômico pesqueiro do entorno imediato da UC, a fim de subsidiar a proposta de regulamentação da atividade de pesca de subsistência no interior do Parque, e dessa forma fomentar o fortalecimento da gestão e monitoramento de biodiversidade e uso de recursos no Mosaico de Áreas Protegidas do Baixo Rio Negro (ICMBIO, 2016).
} 
Figura 5- Reunião com as Comunidades do entorno do PARNA Anavilhanas

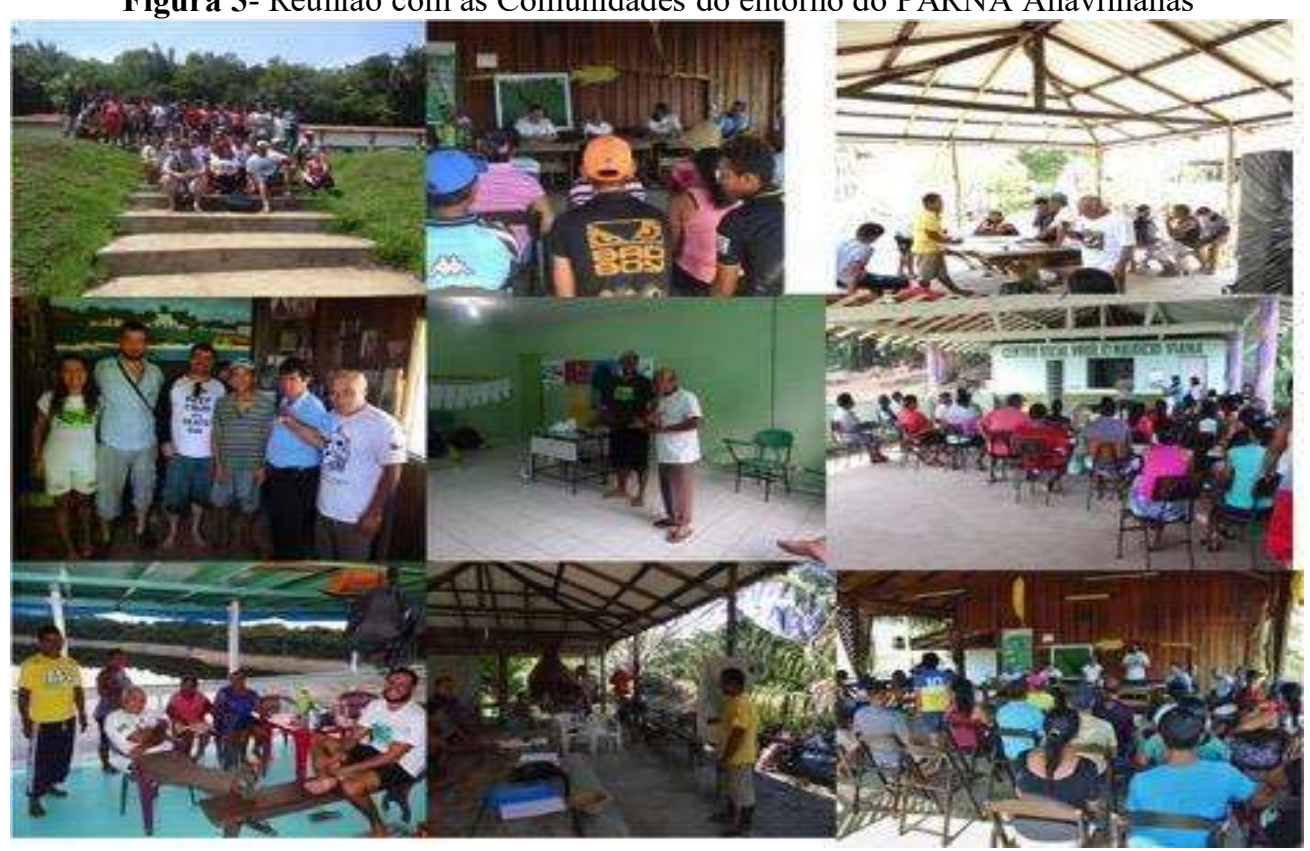

Fonte: ICMBio (2016).

As informações coletadas permitiram caracterizar a pesca de subsistência das comunidades que utilizam áreas do parque e também inferir sobre outros aspectos socioeconômico relevantes, como a importância de outras fontes de recursos na alimentação e economia local, os tipos de produtos cultivados e comercializados e os diversos serviços prestados pelos comunitários.

As reuniões foram realizadas no período de setembro a dezembro de 2015, em 14 polos distribuídos no entorno do PARNA Anavilhanas, incluindo a cidade de Novo Airão. Participaram aproximadamente 431 pessoas representantes de 39 comunidades, sendo 182 entrevistadas. Os dados gerados durante as entrevistas foram apresentados em uma oficina, realizada em Novo Airão, com a presença das comunidades e do ICMBio.

O resultado desse diagnóstico mostrou que a pesca é uma atividade de suma importância econômica para as comunidades localizadas no entorno do Parque, sendo responsável por mais da metade da renda das famílias dos pescadores entrevistados. Assim, conclui-se que 90\% dos comunitários envolvidos na exploração de recursos pesqueiros são pescadores artesanais, sendo apenas $10 \%$ pescadores profissionais (Idem, 2016).

O diagnóstico também evidencia que o PARNA Anavilhanas é a principal área de pesca das comunidades localizas no seu entorno, e também dos pescadores da cidade de Novo Airão, já que os corpos de água presentes nas UCs de entorno do PNA diminuem consideravelmente durante os períodos de seca, restando apenas os lagos e canais no interior do Parque Nacional de Anavilhanas para a aquisição do pescado. 
Devido à localização geográfica das comunidades, o diagnóstico recomenda ser possível estabelecer polos que possam se transformar em unidades de manejo, da mesma maneira. Também ser possível estabelecer essas unidades por meio de sub regiões hidrográficas dentro do parque.

Illeseer (2011) explica que no caso das UCs de proteção integral, onde a tendência é o não reconhecimento formal de um regime de propriedade comum, podem existir diálogos informais entre gestores e usuários. Tais diálogos resultaram em negociações as quais estabeleceram restrições e limites de captura através da determinação de cota por quantidade de pescado e de apetrechos permitidos, tais como zagaia, caniço e malhadeira, principalmente quando isto está relacionado ao direito de subsistência. Nesse sentido, as narrativas de duas lideranças da pesca é ilustrativa:

O ICMBio facilita para nós pescar o mínimo lá dentro, isso por conta deles, fazendo vista grossa, só que há muitas apreensões, porque o pescador não tem consciência, por mais que eu explique e repita eles pegam, tracajá, pegam pirarucu dentro da reserva, mas eles fazem isso para eles sobreviverem. Hoje o ICMBio tenta melhorar a relação com os pescadores, até por que os pescadores ali já estavam quem chegou e se instalou foram as reservas. (Presidente da Colônia Z-34, realizada em outubro de 2017).

Hoje a gente tem uma parceria, não é no papel, mas o ICMBio entende isso que se não for a pesca, a agricultura, a madeira que o cara tira, se não for uma caça ele não sobrevive. Quando acontece algum conflito é porque o pescador tá fazendo alguma coisa errado. Hoje o ICMBio vem aqui no nosso auditório falar dos projetos, o que pode o que não pode, mudou muito, porque antes quando era o IBAMA era mais conflituoso. (Presidente da Colônia AM-34, realizada em outubro de 2017).

Na visão do ICMBio, a realização de acordo informal ajudou a reduzir o número de abordagens de pescadores artesanais de posse de animais silvestres abatidos, principalmente mamíferos e quelônios, ou carregando apetrechos irregulares. O acordo informal possibilitou uma certa cooperação entre a gestão do Parque e os pescadores, resultando num aumento significativo de denúncias feitas pelos ribeirinhos sobre os pescadores de grandes barcos de Manaus que "vinham roubar os peixes dos comunitários às toneladas".

O diagnóstico apresentado pelo ICMBio, em 2016, recomenda que haja o fortalecimento de projetos de extensão nas unidades de conservação do entorno do PARNA, com vistas a discutir, viabilizar e implementar alternativas econômicas para a população ribeirinha moradora do entorno, tanto quanto, uma capacitação nas entidades representativas dos pescadores com vista à coleta de dados sobre desembarque pesqueiro no município de Novo Airão. 


\section{CONCLUSÕES}

Em Novo Airão, exercer a pesca tem sido uma tarefa difícil. A principal difículdade para realizar a atividade pesqueira em Novo Airão, segundo relato dos pescadores artesanais e seus representantes no município, ocorre devido as áreas de conservação, tornarem parte dos ambientes aquáticos não acessíveis para a pesca, o que prejudica sobremaneira a reprodução do modo de vida dos pescadores artesanais. Segundo eles: "Hoje tudo é parque".

Neste cenário, muitos pescadores ignoram as restrições impostas ao acesso dos recursos pesqueiros e entram clandestinamente para pescar no interior dos Parques Nacionais do Jaú e Anavilhanas, principalmente à noite. Em alguns casos, muitos pescadores artesanais são flagrados pelo órgão governamental que fiscaliza as UC, quando esses pescadores são abordados por esses agentes, além do peixe apreendem também o material de pesca (canoa, malhadeira, anzol, dentre outros), causando conflitos entre as partes.

Atualmente, o ICMBio é órgão responsável pela fiscalização e gestão dos parques em Novo Airão e discute, junto com os representantes do segmento pesqueiro, a problemática do uso dos recursos naturais dentro dos parques federais. No entanto, as relações entre os trabalhadores da pesca e o ICMBio não são muito harmoniosas, uma vez que cada territorialidade tem seus objetivos e metas próprios (RODRIGUES, 2014). Enquanto o agente do Estado preocupa-se em manter "intocada a natureza, por outro lado, o pescador procura formas de exercer a pesca clandestinamente, tendo o cuidado de não ser autuado, multado ou ter seus apetrechos de pesca apreendidos pelos agentes do ICMBio, pois da pesca depende o sustento de sua família, além de ser sua principal fonte de trabalho e renda.

Além disso, o município não possui mercados, feiras e nem frigoríficos para armazenar ou beneficiar o pescado. A falta desta infraestrutura acaba favorecendo a atividade dos atravessadores na região. Assim, os pescadores são obrigados a vender sua produção para pequenos comerciantes, donos de restaurantes ou nas residências. A outra opção é vender o pescado para atravessadores por um preço muito baixo. 


\section{REFERÊNCIAS}

ALMEIDA, Alfredo Wagner Berno de. Terra de quilombo, terras indígenas, "babaçuais livre", "castanhais do povo", faixinais e fundos de pasto: terras tradicionalmente ocupadas. - 2." ed, Manaus: pgsca-ufam, 2008.

ARRUDA, R. V. "Populações Tradicionais" e a Proteção dos Recursos Naturais em Unidades de Conservação. In: Congresso Brasileiro de Unidades de Conservação, 1, 1997, Curitiba. Anais, v.1. Curitiba: IAP/Unilivre/Rede Nacional Pró-Unidades de Conservação, 1997, p. 351-67.

BRASIL, SNUC - Sistema Nacional de Unidades de Conservação, Lei no 9.985, de 18 de julho de 2000. Brasília - DF: Senado, 2000.

Decreto. Lei no 10.683, de 28 de maio de 2003. Dispõe sobre a concessão do benefício de seguro desemprego, durante o período do defeso ao pescador artesanal.

Decreto $\mathrm{n}^{0} \mathbf{8 . 4 2 4 / 2 0 1 5}$. Dispõe sobre as regras de acesso ao seguro-defeso.

CREADO, Eliana S. J.; MENDES, A. B. V.; FERREIRA, L. C; CAMPOS, S. V. O Parque Nacional do Jaú e a situação dos moradores de sua parte central: agência ou sujeição?. $31^{\circ}$ Encontro Anual da ANPOCS. Caxambu, MG, 2007.

CARDOSO, T. M. Depoimento: o mosaico do baixo rio Negro. Unidades de Conservação no Brasil, 2010. Disponível em: http://uc.socioambiental.org/territ\%C3\%B3rio/depoimento-o-mosaicodo-baixo-rio-negro. Acessado em: Dezembro de 2016.

DIEGUES, A. C. Conhecimento tradicional e apropriação do ambiente marinho. São Paulo: NUPAUB - USP, 2001.

DIEGUES, A. C. S. O Mito Moderno da Natureza Intocada. São Paulo: Edusp/NUPAUB, 1994.

ESTERCI, Neide. Conflitos ambientais e processos classificatórios na Amazônia brasileira. In: Boletim Rede Amazônia: diversidade sociocultural e políticas ambientais, ano 1, n. 1, 2002.

FURTADO, L. G. Pescadores do rio Amazonas: um estudo antropológico da pesca ribeirinha numa área amazônica. Belém: Museu Paraense Emílio Goeldi, 1993.

FVA/IBAMA. Plano de Manejo do Parque Nacional do Jaú. Manaus: Fundação Vitória Amazônica/IBAMA, maio de 1998. 258p. (Versão 8).

IBGE, Instituto Brasileiro de Geografia e Estatística. Censo Demográfico de 2010. Disponível em: http://www.cidades.ibge.gov.br/xtras/perfil.php?lang=\&codmun=130340 Acesso em: 20/11/2015.

IBGE, Instituto Brasileiro de Geografia e Estatística. Divisão Regional do Brasil em Mesorregiões e Microrregiões Geográficas - Vol I - RJ - 1990.

ILLENSEER, Rafael. Pescadores sem águas: estratégias de adaptabilidade dos pescadores artesanais no Mosaico de Áreas Protegidas do Baixo Rio Negro (AM). Dissertação (Mestrado em Ciências do Ambiente e Sustentabilidade na Amazônia) - Universidade Federal do Amazonas, 2011.

ICMBio. Diagonostico Socioeconomico Pesqueiro do Parque Nacional de Anavilhanas - Manaus, 2016. LITTLE, Paul E. Os Conflitos Socioambientais: um Campo de Estudo e de Ação Política. (Org.) BURSZTYN, M. In: A Difícil Sustentabilidade: Política energética e conflitos ambientais. Rio de Janeiro: Ed. Garamond Ltda. 2001.

LEONARDI, Victor. Os historiadores e os rios: naturezae ruína na Amazônia brasileira. Brasília: Paralelo 12 e Editora da Universidade de Brasília, 1999. 
MOURA, Sarita de. Diagnóstico ambiental urbano da cidade de Novo Airão, Amazonas. Dissertação (Mestrado), Programa de Pós-graduação em Engenharia Urbana, Universidade Federal de São Carlos, São Carlos, 2009, 139 fls.

Moura, Edila Arnaud Ferreira et al. Sociodemograa da Reserva de Desenvolvimento Sustentável Mamirauá: 2001- 2011. Tefé, AM. Instituto de Desenvolvimento Sustentável Mamirauá. Belém: IDSM; NAEA; 2016.310 p.: il.; $23 \mathrm{~cm}$.

PEREIRA, H. dos S. Iniciativa de co-gestão dos recursos naturais da várzea - Estudo do Amazonas - Estudo estratégico Analítico. Manaus:Ibama/ProVárzea, 2004.

RODRIGUES, Fúlvia Maria Gomes. Unidades de Conservação, pesca e modo de vida/contradições. Dissertação (mestrado em Geografia) - Universidade Federal do Amazonas, 2014.

RODRIGUES, Fúlvia Maria Gomes. Pesca em Novo Airão (am) e suas territorialidades em Conflito. Anais XVI Encontro nacional dos Geógrafos. Porto Alegre - RS, 2010.

SILVA, Gimima Beatriz Melo da. Gestão ambiental e desautorização dos moradores em RDS: reserva de desenvolvimento sustentável - do Rio Negro - AM. In: NEVES, DP. GOMES, RA., and LEAL, PF., orgs. Quadros e programas institucionais em políticas públicas [online]. Campina Grande: EDUEPB, 2014, pp. 219-240.

SILVA, Gimima Beatriz Melo da. Guardiões da Floresta, retóricas e formas de controle de gestão ambiental e territorial. 1-ed.- Rio de Janeiro: Letra Capital, 2015.

SILVA, Andréa Leme; BEGOSSI, Alpina. Uso de recursos por ribeirinhos no Médio Rio Negro. In: BEGOSSI, Alpina (org). Ecologia de pescadores da Mata Atlântica e da Amazônia. São Paulo: Hucitec: Nepam/ Nupaub/USP: Fapesp, 2004.

SACHS, Ignacy. População, Tecnologia, Recursos Naturais e Meio Ambiente: In: SACHS, Ignacy. Ecodesenvolvimento: crescer sem destruir. São Paulo: Vértice, 1986.

SIMMEL, Georg. Sociologia. Oorganização de Evaristo de Moraes Filho. São Paulo : Ática, 1983.

VALLEJO, L.R. Unidade de Conservação: Uma Discussão Teórica á Luz dos Conceitos de Território e Políticas Públicas. GEOgraphia, América do Norte, 4, set. 2009.

VIANA, Virgílio. Bolsa Floresta um instrumento inovador para a promoção da saúde em comunidades tradicionais na Amazônia. In: Estudos Avançados. v.22, n.64. São Paulo: Dez. 2008. 